\title{
Effect of bagasse ash reinforcement on Al356 matrix composite manufactured by two stage stir casting process
}

\author{
Vaibhav Dardare* and S. G. Kulkarni \\ Mechanical Engineering Department, Solapur University, SKN Sinhgad College Of Engineering, Korti, Pandharpur, Maharashtra, India.
}

Received 01 May 2018, Accepted 01 July 2018, Available online 02 July 2018, Vol.8, No.4 (July/Aug 2018)

\begin{abstract}
In the present work Al356-Bagasse ash composites are produced by two stage stir casting method and subsequently various properties like compression strength, tensile strength, hardness of Al356 are studied. Al356 alloy is reinforced with bagasse ash particles of the various weight percentage (2,4 and $6 \% \mathrm{wt}$.). An experimental result shows uniform distribution of the bagasse ash particles in the matrix of the Al356 leading to increase in the mechanical strength of the composites. The tensile and compression tests are carried out with the help of Universal Testing Machine and it was observed that ultimate tensile strength, yield strength and compression strength increases with increase weight percentage of bagasse ash in the composite, while percentage elongation decreases. The hardness of the composites are measured by brinell hardness tester and it was observed that hardness of the composite material increases with increase in weight percentage of bagasse ash particles.
\end{abstract}

Keywords: Aluminium matrix, bagasse ash, two stage stir casting, tensile strength, compressive strength, hardness.

\section{Introduction}

A composite material can be defined as a combination of two or more materials that results in better properties than those of the individual components used alone. In contrast to metallic alloys, each material retains its separate chemical, physical, and mechanical properties. The two constituents are a matrix and reinforcement. The main advantages of composite materials are their high strength and stiffness, combined with low density, when compared with bulk materials, allowing for a weight reduction in the finished part.[F. C. Champbell, (2010)]. The composite materials are mostly used in automobile, marine, aerospace industries as it possesses superior strength and low density as compare to isotropic materials. [Gowri Shankar(2017)] The metal matrix composite (MMC) is the combined form of metal as a matrix and hard particles or ceramic as a reinforcement to get improved properties. The idea of composite material is not new in nature many things are made by composite material like coconut palm leaf is a fibre reinforcement because it act as cantilever, wood is cellulose fibers having high tensile strength with low stiffness in lignin matrix joins the fibers and furnish the stiffness as a fibrous composite etc. In Metal Matrix Composites (MMCs) metals like aluminum, beryllium, magnesium, titanium, iron, nickel, cobalt, copper, zinc, and silver

*Corresponding author's ORCID ID: 0000-0002-6943-3803 DOI: https://doi.org/10.14741/ijcet/v.8.4.3 acts as matrix and $\mathrm{SiC}, \mathrm{Al}_{2} \mathrm{O}_{3}, \mathrm{~B}_{4} \mathrm{C}, \mathrm{TiC}, \mathrm{TiB}$, graphite, and a number of other ceramics are act as reinforcement which provide a very desirable combination of stiffness, strength, and relatively low density. By far the largest usage of aluminum as a matrix metal in Aluminum Matrix Composites (AMCs) [W. H. Hunt].

Gowri Shankar M.C. et al (2017) developed the Al6061-SiC by two stage stir casting and found hardness and tensile strength increase at various temprature with increase in weight fraction of reinforcement. N. Subramani et al. (2014) studied hardness behavior of Al-SiC composite by two stage stir casting they found that hardness increases with increase in volume fraction of SiC. Gowri Shankar M. C. et al. (2016) prepared Al6061-SiO2 by two stage stir casting route and shows high hardness and tensile strength. P. Shanmughasundaram and R. Subramanian (2013) fabricated Al-Si Alloy-Graphite Composite by modified two stage stir casting and squeeze casting method showed lower hardness with increasing the weight percent of graphite particles. K. K. Alneme and M. O. Bodunrin (2013) presented the mechanical behavior of Al6063 with alumina (Al203) by two stage stir casting and conclude that tensile strength, yield strength and hardness value of composite increase with increase in volume percent of alumina while strain to fracture and fracture toughness decrease with increase volume percent of alumina. M. Sambathkumar et al. (2016) develop Al7075 hybrid metal matrix composite by two stage stir casting and studied 
corrosion resistance of $\mathrm{SiC}$ and $\mathrm{TiC}$ hybrid reinforcement. Sachin Mohal (2017) Studied microstructure, XRD Analysis and XRF Analysis with uniformly distribution of $\mathrm{SiC}$ particles in Aluminum of Aluminum-Silicon Carbide Particulate by two stage stir casting. P. Shanmughasundaram et al. (2012) fabricated Al-Fly ash by two stage stir casting method and conclude that in microstructure uniform distribution of fly ash and increase hardness with increase in weight percent of fly ash. Kenneth K. Alaneme et al. (2012) studied Age-Hardening behavior of borax premixed $\mathrm{SiC}$ reinforced $\mathrm{Al}-\mathrm{Mg}-\mathrm{Si}$ alloy composite by double stir casting technique. Mandar Valsange et. al (2014) and R V Adat (2016) studied manufacturing of fly ash composite by stir casting method. S. G. Kulkarni (2017) studied effect of fly ash addition on Al356 alloy. B. Admile et. al. (2014) studied effect of fly ash addition on wear behavior of composite.

\section{Material and method}

The main purpose of this paper is to manufacture the aluminium metal matrix composite with varying compositions of reinforcement particles of bagasse ash by using two stage stir casting method. Testing of aluminium metal matrix composite material to carried out to evaluate its mechanical properties.

\subsection{Matrix}

Aluminium 356 used as matrix metal because it is used in number of applications like aircraft pump parts, automotive transmission cases, aircraft fittings and control parts, water-cooled cylinder blocks etc.

The chemical composition of Al356 are established in Table 1

Table 1 Composition of Al356 Alloy

\begin{tabular}{|c|c|c|c|c|c|c|c|}
\hline $\mathrm{Si}$ & $\mathrm{Fe}$ & $\mathrm{Cu}$ & $\mathrm{Mn}$ & $\mathrm{Zn}$ & $\mathrm{Mg}$ & $\mathrm{Ti}$ & $\mathrm{Al}$ \\
\hline 7.24 & 0.26 & 0.17 & 0.24 & 0.10 & 0.43 & 0.05 & $\mathrm{Bal}$ \\
\hline
\end{tabular}

\subsection{Reinforcement}

Reinforcement material used in current work is bagasse ash of size up to $106 \mu$ which is prepared by sieve analysis tester. Bagasse ash generates during the combustion of sugarcane for energy production in sugar factory.

\subsection{Experimental procedure}

Different manufacturing processes are available for manufacturing of composite material. According to $\mathrm{N}$. Subramani et. al. (2014) stir casting process is generally accepted as a particularly promising route, currently practiced commercially. Its advantage lies in its simplicity, flexibility and applicability to large quantity production.
While manufacturing of composite by two stage stir casting method Aluminium 356 alloy ingots which were cut into small pieces with the help of power hack saw was insert into the crucible of furnace for melting purpose and maintain the temperature of furnace $800^{\circ} \mathrm{c}$. At the same time wt. $\%$ of bagasse ash was put into the furnace of temperature $200^{\circ} \mathrm{c}$ for preheating for $2 \mathrm{hr}$. in order to remove the moisture contains, Which results in improving the wettability of the particle. After melting the Aluminium 356 alloy add scum powder for removing slag or flux. After removing slag or flux add hexa chloro ethane $\left(\mathrm{C}_{2} \mathrm{Cl}_{6}\right)$ tablets as a degassifier. Then decrease the temperature of furnace to $620^{\circ} \mathrm{C}$ which is bellow the liquid temperature for allow the melt semisolid stage. Then $1 \%$ of magnesium was added to molten metal for increase wettability. Then the melt was stirred using a mild steel stirrer at 300-400 rpm for 8-10 min. Bagasse-ash particles were added to the melt at the time of formation of vortex in the melt due to stirring. The melt temperature was maintained at 620 oc during the addition of the bagasse ash particles. After stirring process temperature of furnace further increases to $800^{\circ} \mathrm{c}$ and second stirring process done for $10 \mathrm{~min}$. by using same stirrer. Then the melt was casted in a clay graphite crucible and poured continuously into preheated mould cavity. Similar fabrication procedure is carried out for $4,6,8$ and $10 \%$ of bagasse ash. The two stage stir casting setup is shown in fig. 1

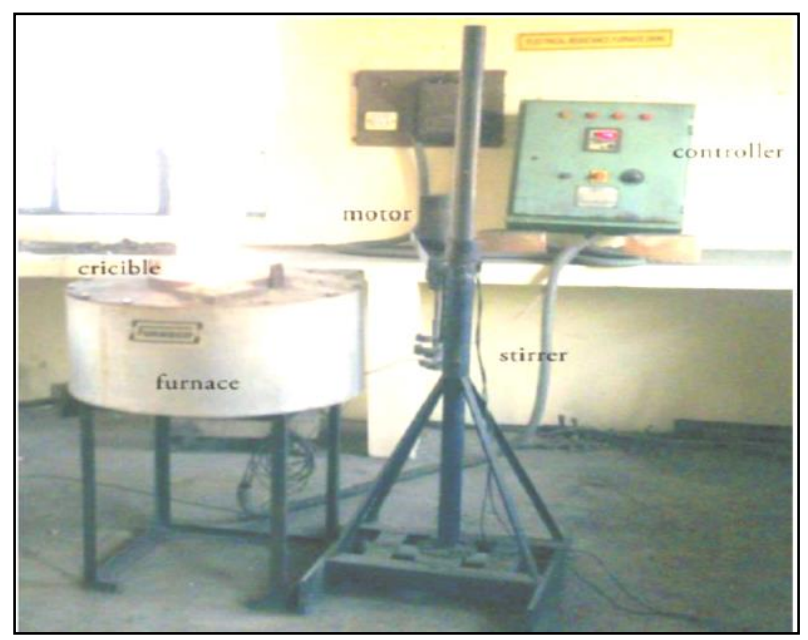

Fig.1 Two stage stir casting set up

\section{Result}

\subsection{Tensile test}

The tensile testing of the composite was done, on Universal testing machine to evaluate tensile properties. A test specimen of circular cross section prepared from composite materials, avoiding sharp changes in section. Specimens are tested as per ASTM E8.

The various strength obtained by tensile strength is shown in Table 2. 
Table 2 Tensile properties of composite at various wt. \% of bagasse ash

\begin{tabular}{|c|c|c|c|c|}
\hline Sr. No. & Composition & UTS, MPa & Yield Stress, MPa & \% Elongation \\
\hline 1 & Pure Al Alloy & 151.27 & 120.84 & 2.78 \\
\hline 2 & Al356 + $\%$ Bagasse ash & 172.25 & 123.84 & 2.19 \\
\hline 3 & Al356 + 4\% Bagasse ash & 184.85 & 132.15 & 1.74 \\
\hline 4 & Al356 $+6 \%$ Bagasse ash & 193.00 & 132.00 & 1.67 \\
\hline
\end{tabular}

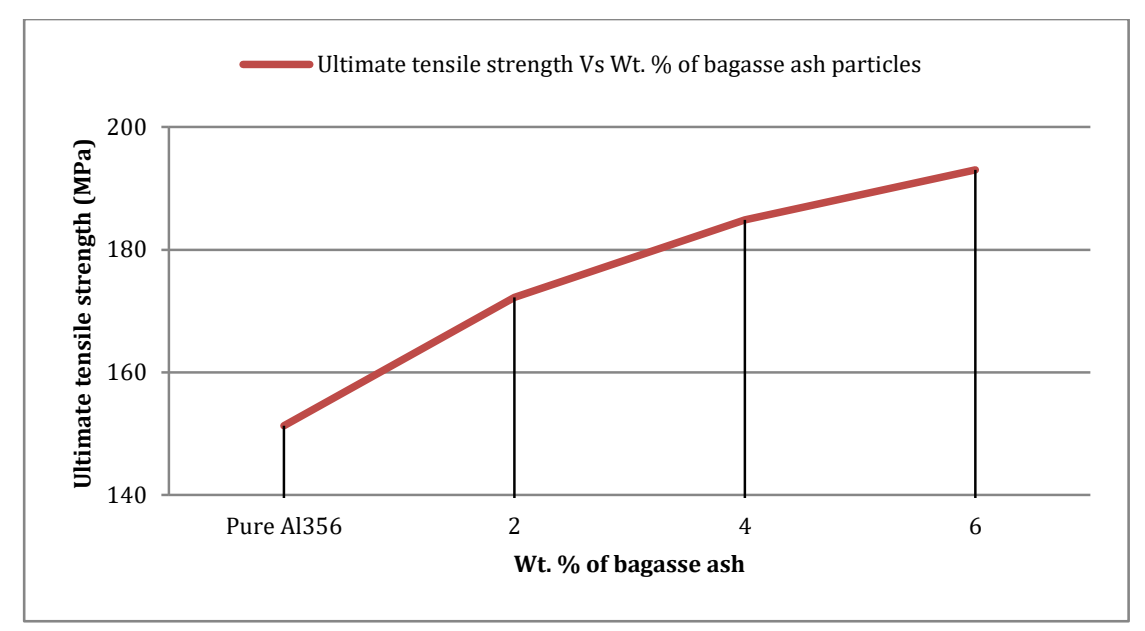

Fig.2 Ultimate tensile strength Vs. wt. \% of bagasse ash

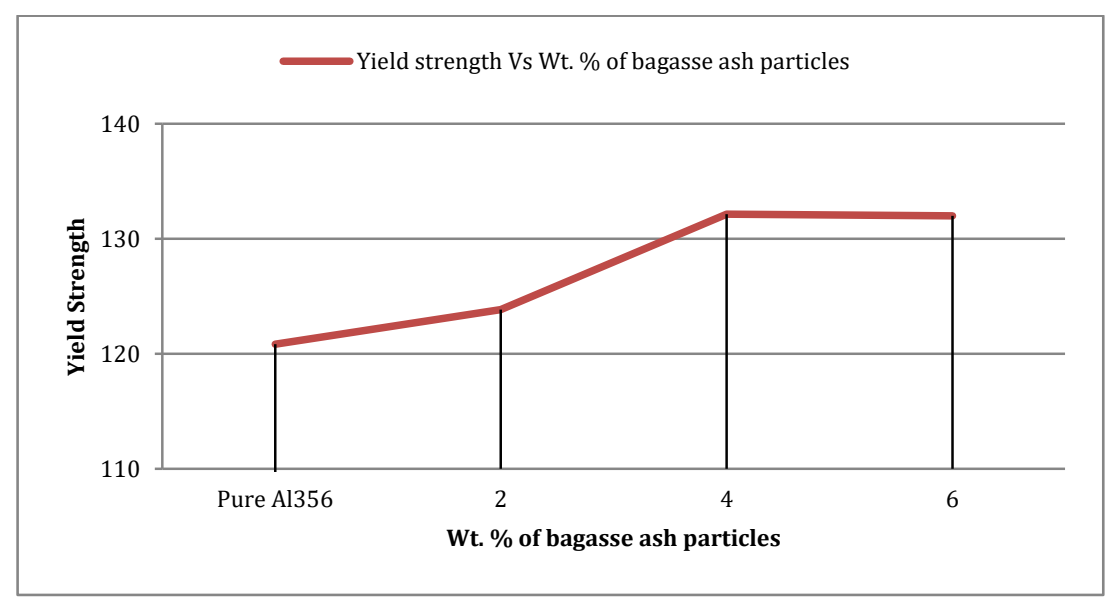

Fig.3 Yield strength Vs. wt. \% of bagasse ash

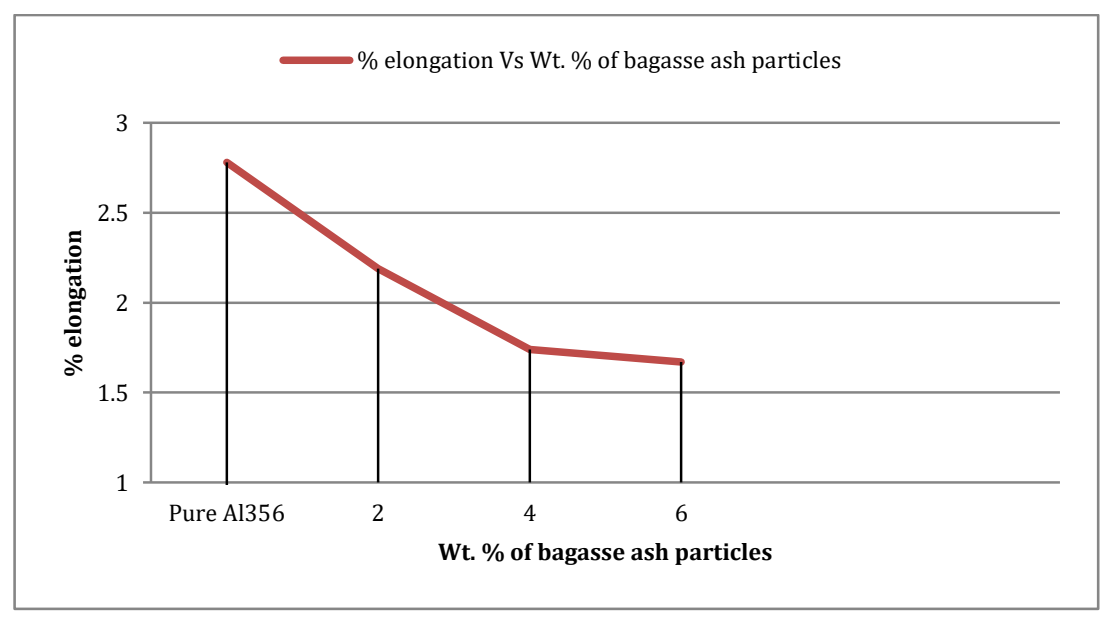

Fig.4 \% elongation Vs. wt. \% of bagasse ash 
It is observed that tensile properties of Al356 composite material like ultimate tensile strength, yield strength increases with increasing wt. percentage of bagasse ash. While percentage elongation decreases with increasing wt. percentage of bagasse ash. The graphical representation of ultimate tensile strength, yield strength and elongation Vs. wt. percentage of bagasse ash is shown in fig. 2,3 and 4 respectively.

\subsection{Compressive strength}

The compressive strength of Al356 metal matrix composite material was done on UTM. Samples were prepared as per ASTM E9, so length of specimen is 25 $\mathrm{mm}$ and diameter is $13 \mathrm{~mm}$. Further samples are polished to achieve flat surfaces with emery paper. The compressive test result is shown in Table 3

Table 3 Compressive strength of composite at various wt. \% of bagasse ash

\begin{tabular}{|c|c|c|}
\hline Sr. No & Composition & UCS (MPa) \\
\hline 1 & Pure Al Alloy & 661.216 \\
\hline 2 & Al356 + $\%$ Bagasse ash & 676.386 \\
\hline 3 & Al356 + 4\% Bagasse ash & 686.56 \\
\hline 4 & Al356 + 6\% Bagasse ash & 690.00 \\
\hline
\end{tabular}

While taking compressive test the compressive load was act on the composite material of various wt. percent of reinforcement up to the first crack observed on composite that is when shearing start. It was observed that ultimate compressive strength of Al356 composite material increases with increase in wt. percentage of bagasse ash. The graphical representation of UCS Vs. wt. \% of bagasse ash is shown in fig. 5

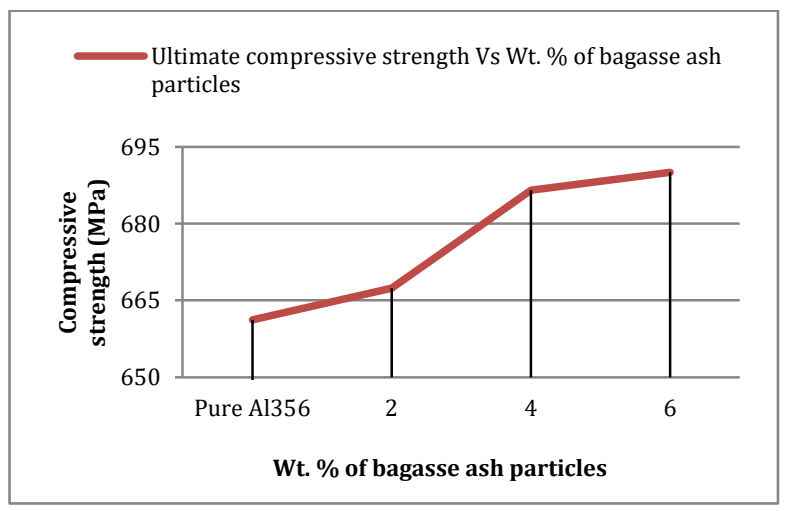

Fig.5 Ultimate compressive strength Vs. wt. \% of bagasse ash

\subsection{Hardness}

For brinell hardness test surface being tested generally requires metallographic surface finish and it was done with help of $100,220,400,600$ and 1000 grit size emery papers. Results of brinell hardness test on pure $\mathrm{Al}$ alloy and varying reinforced MMC are shown in Table 4
Table 4 Hardness of composite at various wt. \% of bagasse ash

\begin{tabular}{|c|c|c|}
\hline Sr. No. & Composition & Mean Hardness (BHN) \\
\hline 1 & Pure Al Alloy & 76 \\
\hline 2 & Al356 $+2 \%$ Bagasse ash & 78.22 \\
\hline 3 & Al356 $+4 \%$ Bagasse ash & 79.5 \\
\hline 4 & Al356 $+6 \%$ Bagasse ash & 81.50 \\
\hline
\end{tabular}

It is observed that the hardness of composite increase with increase in wt. percentage of bagasse ash. The graphical representation of brinell hardness no. Vs. wt. percentage of bagasse ash is shown in fig. 6

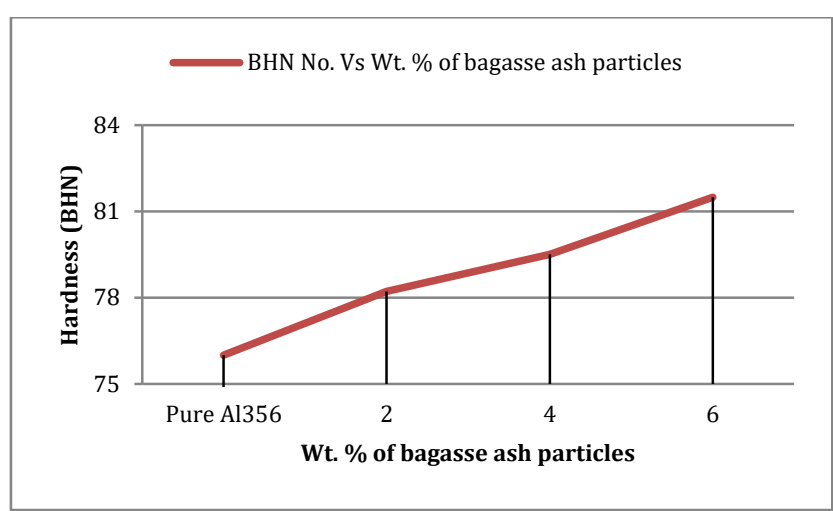

Fig.1 Brinell hardness no. Vs. wt. \% of bagasse ash

\section{Conclusions}

1) Two stage stir casting method is effective method of fabrication of composite material amongs the other methods, because in this method homogenous mixture of matrix and reinforcement done.

2) The mechanical properties of composite material is more as compare to Al356 alloy

3) After performing tensile test it is observed that the ultimate tensile strength, yield strength of the composite material is increases by increasing the weight percentage of bagasse ash.

4) The percentage elongation of composite decreases when the weight percentage of bagasse ash increases. The percentage elongation of composite material is less than the base Al356 alloy.

5) The ultimate compressive strength and hardness of the composite material increases with increase in weight percentage of bagasse ash in the composite material.

6) Use of bagasse ash as a reinforcement in Al356 alloy increases the mechanical strength of the composite material. This is the one of the way to dispose sugarcane factory waste.

\section{References}

Gowri Shankar M.C., S.S. Sharma., Achutha Kini U, Pavan Hiremath, Gurumurthy., (2017) Microstructure and fracture behaviour of two stage stir cast Al6061-SiC composites, Journal of materials and Environmental Sciences (JMES), Volume 8, PP 257-263. 
Kulwinder Singh, Sanjeev Kumar., (2016) Fabrication of AlSiC Metal Matrix Composites Using Two Steps Mixing in Stir Casting, International Journal for Research in Applied Science \& Engineering Technology (IJRASET), Volume 4, ISSN: 2321-9653.

Mohammed Imran, A.R. Anwar Khan, Sadananda Megeri, Shoaib Sadik., (2016) Study of hardness and tensile strength of Aluminium-7075 percentage varying reinforced with graphite and bagasse-ash composites, Efficient technologies, Volume 2, Issue 14 May 2016, PP 81-88.

N.Subramani, M.Balamurugan, K.Vijayaraghavan, (2014) Mechanical Behaviour of Al-SiC Composites Prepared By Stir Casting Method, International Journal of Innovative Research in Science, Engineering and Technology., Vol. 3, ISSN: 2319-8753.

S. G. Kulkarni, J. V. Meghnani, Achchhe Lal., (2014) Effect of fly ash reinforcement on mechanical property and density of Aluminium 356 alloy, Procedia material science, Volume 5, PP. 746-754

V.S. Aigbodion, (2014) Thermal ageing on the microstructure and mechanical properties of $\mathrm{Al}-\mathrm{Cu}-\mathrm{Mg}$ alloy/bagasse ash particulate composites, Journal of King Saud University Engineering Sciences, PP144 -151.

K. K. Alaneme, M. O. Bodunrin., (2013), Mechanical behaviour of aluminium reinforcement AA 6063 metal matrix composite developed by two step stir casting, Acta technical corveninsis bulletin of engineering, Volume 5.
P. Shanmughasundaram, R. Subramanian, G. Prabhu., (2011) Some Studies on Aluminium - Fly Ash Composites Fabricated by Two Step Stir Casting Method, European Journal of Scientific Research, Vol.63 No.2, PP.204-218.

F. C. Champbell, (2010) Stuctural composite material ASM International.

M Valsange, SG Kulkarni, SA Sonawane, (2014) Stir casting used in manufacturing of aluminium matrix composite, International Journal for Research in Technological Studies 1 (9), 35-38

SG Kulkarni, JV Menghani, A Lal, (2016)Investigation of mechanical properties of fly ash and Al 203 reinforced A356 alloy matrix hybrid composite manufactured by improved stir casting, NISCAIR-CSIR, India.

B Admile, S G Kulkarni, SA Sonawane, (2014)Application of Taguchi method for optimization of process parameters for wear loss of LM25/Fly ash composite, International Journal of Innovations in Engineering and Technology 4 (4), 24-29

SG Kulkarni, A Lal, M JV, (2017) Numerical investigation of clustering effect on the uniaxial stress strain behaviour of A356 matrix composite, ICMPC.

RV Adat, SG Kulkarni, SS Kulkarni, (2016) Manufacturing of particulate reinforced aluminum metal matrix composites using stir casting process, International Journal of Current Engineering and Technology 5 (4), 2808-2812 